\title{
Knowledge and Attitude of Health Professionals Towards Clinical Pharmacy Services in Selected Hospitals in West Shoa Zone, Ethiopia
}

\author{
Esayas Tadesse Gebremariam, Getu Melesie Taye ${ }^{*}$, Diriba Alemayehu \\ Department of Pharmacy, Ambo University, Ambo, Ethiopia \\ Email address: \\ esayastadesse23@yahoo.com (E. T. Gebremariam), getumelese17@gmail.com (G. M. Taye), direalexphar@ymail.com (D. Alemayehu) \\ ${ }^{*}$ Corresponding author
}

\section{To cite this article:}

Esayas Tadesse Gebremariam, Getu Melesie Taye, Diriba Alemayehu. Knowledge and Attitude of Health Professionals Towards Clinical Pharmacy Services in Selected Hospitals in West Shoa Zone, Ethiopia. Biomedical Statistics and Informatics. Vol. 5, No. 1, 2020, pp. 9-13. doi: $10.11648 /$ j.bsi.20200501.12

Received: September 6, 2019; Accepted: October 26, 2019; Published: January 9, 2020

\begin{abstract}
Clinical pharmacy services are patient oriented services developed to promote the rational use of medicines by maximizing therapeutic effect of medicines in individual patients. The service is at the infant stage in Ethiopia and there is no adequate information about it in the country. Therefore, the aim of this study was to assess the knowledge, attitude \& practice of health professionals towards clinical pharmacy services in selected public hospitals in West Shoa Zone, Oromia Region, Ethiopia. A facility based cross sectional survey was conducted from April 2 to April 16, 2018. The study used a quantitative method of data collection. A total of 150 health professionals were involved in the study; and convenience sampling techniques was used to collect the data. Data was collected using structured and self-administered questionnaires and it was analyzed by using SPSS version 23. Descriptive statistics including frequency, mean, percentage and table was used to present the data. 128 (92.1\%) of health professionals were heard about clinical pharmacy services in Ethiopia. $104(74.8 \%)$ strongly agreed \& agreed that they appreciated the presence of pharmacist in the ward all the times important for patient care. However, 67 (48.2\%) of respondents said the performance of the pharmacists in practicing clinical pharmacy in the hospital was poor. Generally, majority of health professionals had adequate knowledge and positive attitudes towards clinical pharmacy services but their practice with clinical pharmacists was found poor. It is recommended that collaborative working relationship should be established among health professionals in order to optimize and monitor drug use problem in the hospitals.
\end{abstract}

Keywords: Knowledge, Attitude, Clinical Pharmacy, Health Professionals

\section{Introduction}

The World Health Organization (WHO), define a health system "consists of all organizations, people and actions whose primary intent is to promote restore or maintain health". Current WHO Framework for Action on health systems describes six clearly defined Health System Building Blocksthat together constitute a complete system. one of the building block of a health system is Service delivery which includes effective, safe, and quality personal and non-personal health interventions that are provided to those in need, when and where needed (including infrastructure), with a minimal waste of resources [1].

Hospital is a health care institution, which pools together all the health professionals, the diagnostic and therapeutic facilities \& the physical facilities in to a coordinated system for delivering health care service to the public [2].

Pharmaceutical services are an essential component of hospital care and clinical pharmacy services are patient oriented services developed to promote the rational use of medicines and more specifically to maximize therapeutic effect, minimize risk, minimize cost and respect patient choice and decisions there by ensuring the safe, effective and economic use of drug treatment in individual patients [3, 4].

The mission of the pharmacist is to provide pharmaceutical care [5]. Pharmaceutical care is the direct responsible provision of drug therapy for the purpose of achieving definite outcomes that improve patient's quality of 
life. It refers the process through which a pharmacist cooperates with a patient and other professionals in designing, implementing, and monitoring a therapeutic plan that will produce specific therapeutic outcomes for the patient. These outcomes are cure, reemission, or prevention of a disease [6].

The positive impact of pharmaceutical care services on clinical, economic and humanistic outcomes has been demonstrated in numerous studies in the North America and United Kingdom. Despite this, there is much variability between / among countries in the practice and implementation of clinical pharmacy. Pharmaceutical care practice is still in its early stages, in developing countries \& even in most European countries. It is intended to meet a need in the health care system that has arisen due to the increase in complexity of drug therapy and the significant level of drug-related morbidity and mortality associated with drug use. Therefore, the introduction of pharmaceutical care is required in developing countries to aid in the resolution of medication-related problems [7].

Clinical pharmacy practice is at the infant stage in Ethiopia. The Ethiopian health authorities have sought to implement clinical pharmacy service within the nation's health-care system in order to improve patients' quality of life and drug use [8]. Therefore, the aim of this study is to evaluate the knowledge, attitude \& practice of health professionals towards clinical pharmacy services in selected public hospitals in West Shoa Zone, Oromia Region, Ethiopia.

\section{Methods}

A facility based cross sectional survey was conducted on health professionals found in Gudar, Ambo General and Referral Hospitals from April 2 to April 16, 2018. The study used a quantitative method of data collection. All health professionals found in the selected health facilities were the source population and sampled health professionals were included as study population. The sample size to be included in the study was calculated based on standard formula, and a total of 150 health professionals were involved in the study. convenience sampling techniques was used to collect the data. A structured questionnaire was used to gather data on back ground information of the facility and pharmacy case team, while a self-administered questionnaire used to collect information on knowledge, attitude and rate of satisfaction of health professionals towards the current clinical pharmacy practice in the facility. After the data was manually checked for completeness and consistencies, it was entered and analyzed by using SPSS version 23. Descriptive statistics including frequency, mean, percentage and table was used to present the data. Ethical approval was obtained from the head department of Pharmacy, Ambo University and from the respective health facilities. Besides, a verbal consent was obtained from all participants before starting the actual data collection. Confidentiality and anonymity of information was maintained throughout the data collection and analysis period by not linking personal identifiers in the data presentations.

\section{Results}

\section{Socio-demographic characteristics of respondents}

A total of 150 self-administered questionnaire were distributed to health professionals found in the study health facilities; from these 139 questionnaires were completed and returned to the investigator resulting in the response rate of $92.7 \%$. The mean age of the respondent was 32.6 years (SD =3.78). The minimum age was 21 and the maximum was 48 . Professionally, 26 (18.7\%) of respondents were physicians; $22(15.8 \%)$ werePharmacists\& druggists; 72 (51.8\%) were nursesand $8(5.8 \%)$ were midwiferies. Most of the respondents, $71(51.1 \%)$ were having 5-7 years of work experience as shown in Table 1.

Table 1. Socio demographic characteristics of health professionals working in the selected public health facilities in West Shoa Zone, Ethiopia, April $2018(n=139)$.

\begin{tabular}{llll}
\hline Socio-demographic Profile & Number & Percentage \\
\hline \multirow{2}{*}{ Sex } & Male & 88 & 63.3 \\
& Female & 51 & 36.7 \\
Age & $20-29$ & 97 & 69.8 \\
& $30-39$ & 35 & 25.2 \\
& $\geq 40$ & 7 & 5.0 \\
& Specialist & 4 & 2.9 \\
& General Practitioner & 26 & 18.7 \\
Profession & Pharmacy & 22 & 15.8 \\
& Nurse & 72 & 51.8 \\
& Laboratory & 4 & 2.9 \\
& Midwifery & 8 & 5.7 \\
& Anesthesia & 2 & 1.4 \\
Level of & Physiotherapy & 1 & 0.7 \\
education & Diploma/ Level IV & 34 & 24.5 \\
& Bachelor/ First & 105 & 75.5 \\
Work & Degree & 62 & 44.6 \\
experience & <5 years & 71 & 51.1 \\
& 5-10 years & 6 & 4.3 \\
\hline
\end{tabular}

Knowledge of health professionals towards the clinical pharmacy services

The 139 health professionals were asked if they heard about clinical pharmacy services in Ethiopia, and the response of $128(92.1 \%)$ health professionals were yes and the remaining $11(7.9 \%)$ health professionals said no. Majority of the respondents $121(87.1 \%)$ knew that there were clinical pharmacists in their institution and the 18 $(12.9 \%)$ of health professionals didn't know that the presence of clinical trained pharmacists in the institution. $125(89.9 \%)$ of health professionals knew that clinical trained pharmacists are integral part of medical team, improve the patients' health related quality of life, and their involvement reduce adverse drug reaction $\&$ health care costs (table 2). 
Table 2. Knowledge of health professionals towards clinical pharmacy services in the selected public health facilities in West Shoa Zone, Ethiopia, April 2018 $(n=139)$.

\begin{tabular}{|c|c|c|}
\hline Statements & Yes $(\%)$ & No $(\%)$ \\
\hline I have heard about clinical pharmacy services in Ethiopia & $128(92.1)$ & $11(7.9)$ \\
\hline I know that there are clinical pharmacists in our hospital & $121(87.1)$ & $18(12.9)$ \\
\hline I know that clinical pharmacists are integral part of medical teams & $125(89.9)$ & $14(10.9)$ \\
\hline I know that clinical pharmacists attend ward round & $111(79.8)$ & $28(20.1)$ \\
\hline I know that clinical pharmacists attend morning session & $107(77)$ & $32(23.0)$ \\
\hline I know that clinical pharmacists improve the patients' health related quality of life & $97(69.8)$ & $42(30.2)$ \\
\hline I know that clinical pharmacists are capable of offering primary care to the patients & $85(61.2)$ & $54(38.8)$ \\
\hline I have the information about clinical pharmacists role in intensive care unit & $41(29.5)$ & $98(70.5)$ \\
\hline I know that involvement of clinical pharmacists can reduce adverse drug reaction & $118(84.9)$ & $21(15.1)$ \\
\hline I know that involvement of clinical pharmacists can reduce health care costs & $112(80.6)$ & $27(19.4)$ \\
\hline
\end{tabular}

Health professionals' attitude towards clinical pharmacy services

Concerning the attitude of health professionals towards clinical pharmacy service, majority of the respondents had a positive attitude to most of attitude related given statement. No health professionals had highly negative attitude towards the involvement of clinical trained pharmacist in ward round, their role in patient education and counseling, provide relevant drug information to health care professionals and detect and prevent medication use error. 79 (56.8\%) participants said that they felt confidence when there is clinical pharmacist in the ward/outpatient and $83(59.7 \%)$ strongly agreed \& agreed that they appreciated the presence of clinical pharmacist in the ward all the times important for patient care.

Only $23(16.5 \%)$ of health professionals working in medical ward strongly agreed that the current set up (infrastructure and environment) of their hospital is appropriate for the provision of clinical pharmacy services (table 3).

Table 3. Attitude of health professionals towards clinical pharmacy services in the selected public health facilities in West Shoa Zone, Ethiopia, April 2018 $(n=139)$.

\begin{tabular}{|c|c|c|c|c|c|}
\hline \multirow[b]{2}{*}{ Given statements of attitude } & \multicolumn{5}{|c|}{ Frequency of level of attitude } \\
\hline & $\begin{array}{l}\text { Strongly } \\
\text { agree }(\%)\end{array}$ & Agreen (\%) & $\begin{array}{l}\text { Neutral } \\
\text { n (\%) }\end{array}$ & $\begin{array}{l}\text { Disagree } \\
\text { n (\%) }\end{array}$ & $\begin{array}{l}\text { Strongly } \\
\text { disagree }(\%)\end{array}$ \\
\hline $\begin{array}{l}\text { Do you think that Clinical pharmacists' involvement in ward round is } \\
\text { desirable? }\end{array}$ & $50(36.0)$ & 54 (38.9) & $31(22.3)$ & $4(2.8)$ & $0(0)$ \\
\hline $\begin{array}{l}\text { Do you think that Clinical pharmacist can play important role in patient } \\
\text { education and counseling? }\end{array}$ & $55(39.6)$ & $73(52.5)$ & $7(5.1)$ & $4(2.8)$ & $0(0)$ \\
\hline $\begin{array}{l}\text { Do you think that Clinical pharmacist can monitor patient response to drug } \\
\text { therapy from toxicity/side effects perspective? }\end{array}$ & $64(46.1)$ & $67(48.2)$ & $5(3.6)$ & $2(1.4)$ & $1(0.7)$ \\
\hline $\begin{array}{l}\text { Do you think that Clinical pharmacist can monitor patient response to drug } \\
\text { therapy from effectiveness perspective? }\end{array}$ & $38(27.3)$ & $60(43.3)$ & $36(25.9)$ & $4(2.8)$ & $1(0.7)$ \\
\hline $\begin{array}{l}\text { Do you think that clinical pharmacist can involve in drug selection (drug, } \\
\text { dosage form) based on patient and drug factors? }\end{array}$ & $74(53.3)$ & $34(24.5)$ & $19(13.7)$ & $9(6.5)$ & $3(2.2)$ \\
\hline $\begin{array}{l}\text { Do you think that Clinical pharmacist can provide relevant drug information } \\
\text { to health care professionals? }\end{array}$ & $40(28.8)$ & $80(57.4)$ & $16(11.5)$ & $3(2.2)$ & $0(0)$ \\
\hline $\begin{array}{l}\text { Do you think that Clinical pharmacist can detect and prevent medication use } \\
\text { errors? }\end{array}$ & $49(35.3)$ & $54(38.8)$ & $33(23.7)$ & $3(2.2)$ & $0(0)$ \\
\hline Do you think that Clinical pharmacy services enhance patient's satisfaction? & $26(18.7)$ & $45(32.5)$ & $49(35.3)$ & $16(11.5)$ & $3(2.2)$ \\
\hline $\begin{array}{l}\text { Do you think that Clinical pharmacist should take patient's medication } \\
\text { history at admission? }\end{array}$ & $34(24.5)$ & $21(15.1)$ & $58(41.7)$ & $24(17.3)$ & $2(1.4)$ \\
\hline $\begin{array}{l}\text { Do you think that Clinical pharmacists should have access to patient's chart } \\
\text { and have a place to document their services? }\end{array}$ & $19(13.7)$ & $34(24.5)$ & $66(47.5)$ & $18(12.9)$ & $2(1.4)$ \\
\hline $\begin{array}{l}\text { Do you think that Clinical pharmacist analyzes patient treatment and suggest } \\
\text { changes of therapy when necessary? }\end{array}$ & $25(17.9)$ & $30(21.6)$ & $45(32.5)$ & $36(25.9)$ & $3(2.2)$ \\
\hline $\begin{array}{l}\text { Do you think that Pharmacists should also focus on patient care not only } \\
\text { drug products? }\end{array}$ & $28(20.1)$ & $53(38.1)$ & $49(35.3)$ & $8(5.8)$ & $1(0.7)$ \\
\hline $\begin{array}{l}\text { Do you think that The current set up (infrastructure and environment) of } \\
\text { your hospital is appropriate for the provision of clinical pharmacy services? }\end{array}$ & $5(3.6)$ & 18 (12.9) & 43 (30.9) & $51(36.7)$ & $22(15.8)$ \\
\hline $\begin{array}{l}\text { Do you think that Clinical pharmacy service implementation is desirable in } \\
\text { health care system? }\end{array}$ & $30(21.6)$ & $72(51.8)$ & $33(23.8)$ & $4(2.8)$ & $0(0)$ \\
\hline $\begin{array}{l}\text { Do you think that Clinical pharmacists can improve over all patient } \\
\text { outcome/quality of patient care? }\end{array}$ & $26(18.7)$ & $88(63.3)$ & $17(12.3)$ & $6(4.3)$ & $2(1.4)$ \\
\hline $\begin{array}{l}\text { Do you appreciate the presence of clinical pharmacists in the wards all the } \\
\text { times important for patient care? }\end{array}$ & $29(20.9)$ & $54(38.9)$ & $25(17.9)$ & $22(15.8)$ & $9(6.5)$ \\
\hline Do you feel confidence when there is clinical pharmacist in the ward/OPD? & $24(17.3)$ & $55(39.7)$ & $31(22.3)$ & $25(17.9)$ & $4(2.8)$ \\
\hline
\end{tabular}


Regarding the current practice of clinical trained pharmacists in the hospital, $67(48.2 \%)$ health professionals said the performance of the pharmacists in practicing clinical pharmacy in the hospital was poor. More than $50 \%$ of the health professionals responded the practice of clinical pharmacists in dose adjustment for pediatrics and patients with impaired renal and/or liver function, counseling patients during discharge, document their services in patient care and their participation in bedside discussions to assist clinicians on therapeutic care plan and drug selection were unsatisfied.

Concerning the overall level of satisfaction towards the current clinical pharmacy services in the hospital; 72 $(51.8 \%)$ health professionals were poorly satisfied by the services while $31(22.3 \%)$ of respondents said they were fairly satisfied.

Table 4. Attitude of health professional towards practice of clinical pharmacy services in the selected public health facilities in West Shoa Zone, Ethiopia, April $2018(n=139)$.

\begin{tabular}{|c|c|c|c|c|c|}
\hline \multirow{2}{*}{ Clinical pharmacists activity } & \multicolumn{5}{|c|}{ Frequency of the respondent $n(\%)$} \\
\hline & Excellent (\%) & v. $\operatorname{good}(\%)$ & Good (\%) & Satisfactory (\%) & Poor (\%) \\
\hline Clinical pharmacists present in the ward & $8(5.8)$ & $18(12.9)$ & $22(15.8)$ & $24(17.3)$ & $67(48.2)$ \\
\hline $\begin{array}{l}\text { Clinical pharmacists actively participate in ward rounds with the health } \\
\text { care team }\end{array}$ & $12(8.6)$ & $26(18.7)$ & $18(12.9)$ & $19(13.7)$ & $64(46.1)$ \\
\hline Clinical pharmacists provide timely information on drug availability & $9(6.5)$ & $17(12.2)$ & $20(14.4)$ & $24(17.3)$ & $69(49.6)$ \\
\hline $\begin{array}{l}\text { Clinical pharmacists provide information on appropriate route of drug } \\
\text { administration }\end{array}$ & $10(7.2)$ & $23(16.6)$ & $31(22.3)$ & $33(23.7)$ & $45(32.5)$ \\
\hline $\begin{array}{l}\text { Clinical pharmacists participate in preventing, detecting and resolving } \\
\text { any drug interaction }\end{array}$ & $7(5.0)$ & $15(10.8)$ & $25(17.9)$ & $36(25.9)$ & $56(40.4)$ \\
\hline Clinical pharmacists involve in side effect prevention and management & $10(7.2)$ & $23(16.6)$ & $17(12.2)$ & $32(23.0)$ & $57(41.0)$ \\
\hline $\begin{array}{l}\text { Clinical pharmacists counsel patients regarding the safe \&appropriate } \\
\text { use of medications }\end{array}$ & $12(8.7)$ & $16(11.5)$ & $28(20.1)$ & $29(20.8)$ & $54(38.9)$ \\
\hline Clinical pharmacist counsel patients during discharge & $7(5.0)$ & $16(11.5)$ & $19(13.7)$ & $34(24.5)$ & $63(45.3)$ \\
\hline Clinical pharmacists document their services in patient care & $7(5.0)$ & $16(11.5)$ & $16(11.5)$ & $34(24.5)$ & $66(47.5)$ \\
\hline Clinical pharmacists participate in dose calculation for patients & $7(5.0)$ & $11(7.9)$ & $25(17.9)$ & $30(21.6)$ & $66(47.5)$ \\
\hline Clinical pharmacist identify and report adverse drug reaction & $20(14.4)$ & $32(23.0)$ & $20(14.4)$ & $22(15.8)$ & $45(32.5)$ \\
\hline Clinical pharmacists provide information on alternative drug regimen & $15(10.8)$ & $25(17.9)$ & $32(23.0)$ & $23(16.6)$ & $44(31.7)$ \\
\hline Clinical pharmacists advise on cost effective medications & $7(5.1)$ & $10(7.2)$ & $22(15.8)$ & $43(30.9)$ & $57(41.0)$ \\
\hline $\begin{array}{l}\text { Clinical pharmacists participate in dose adjustment for pediatrics and } \\
\text { patients with impaired renal and/or liver function }\end{array}$ & $7(5.1)$ & $10(7.2)$ & $22(15.8)$ & $33(23.7)$ & $67(48.2)$ \\
\hline $\begin{array}{l}\text { Clinical pharmacist actively participate in bedside discussions to assist } \\
\text { clinicians on therapeutic care plan and drug selection }\end{array}$ & $1(0.7)$ & $10(7.2)$ & 25 (17.9) & $31(22.3)$ & $72(51.9)$ \\
\hline $\begin{array}{l}\text { Overall level of satisfaction towards the current clinical pharmacy } \\
\text { services in your setting }\end{array}$ & $1(0.7)$ & $10(7.2)$ & 25 (17.9) & $31(22.3)$ & $72(51.9)$ \\
\hline
\end{tabular}

\section{Discussion}

The practice of pharmacy has changed significantly in recent years. This, invariably, will necessitate changes in procedures and training, and may require more resources, imaginative use of pharmacy skills, and involvement of clinical pharmacists at prescribing and dispensing stages [9]

In this study majority of health professionals had adequate knowledge and positive attitudes towards clinical pharmacy services but their practice with clinical pharmacists was found poor. This finding was in keeping with the results from a cross sectional study of attitudes and perceptions of healthcare providers and medical Students towards clinical pharmacy services in United Arab Emirates (UAE), in which the knowledge and attitude of most of the physicians were good because of most of them are recent graduate and they know the contribution of pharmacists well [10].

About $12 \%$ of the health professionals did not know the availability of clinical pharmacists in their hospital. Even though it is now more than five year since the clinical pharmacy services implemented in Ethiopia, no significant changes in increasing the awareness of other professionals were made by clinical pharmacists themselves, hospital drug and therapeutic committee or by the management, thus large number of health professionals said that they do not know the presence of clinical pharmacists in their hospital.

Concerning the attitude of health professionals towards clinical pharmacy service, majority of the respondents had a positive attitude to most of attitude related given statement. This finding was in line with a study done in UAE reported that $75 \%$ medical students perceived that the clinical pharmacists are important part of the healthcare team. On the other hand, $82 \%$ believed that clinical pharmacists can help improve the quality of medical care in hospitals [11]. Furthermore, a study done by Gelaw et al revealed that general practitioners have a positive attitude towards pharmacists about their insertion into the primary health care panel and an expansion of their role in relation to medicines; however, there was small support for the thought of pharmacists undertaking screening and running therapeutic monitoring clinics [12].

In this study only $23(16.5 \%)$ of health professionals working in medical ward strongly agreed that the current set up (infrastructure and environment) of their hospital is appropriate for the provision of clinical pharmacy services. This finding was similar with the study done in UAE in which $53 \%$ of the respondents reported that they did not have better setup for clinical pharmacy services in their 
institutions. Nevertheless, there was substantial willingness among physicians and nurses to cooperate with clinical pharmacists [13].

In the present study, more than $50 \%$ of the health professionals responded the practice of clinical pharmacists in dose adjustment for pediatrics and patients with impaired renal and/or liver function, counseling patients during discharge, document their services in patient care and their participation in bedside discussions to assist clinicians on therapeutic care plan and drug selection were unsatisfied. However, other studies showed that high satisfaction of health professionals on clinical pharmacists' contribution to patient care in the hospitals by conducting ward rounds, monitor drug therapies and most importantly educate patient by the bedside. Moreover, they also perform a major role in provision of ambulatory clinical setups by providing intensive patient education and consultation to the prescribers [14]. This may be due to, in the developed countries, the improved interaction among physicians and pharmacist has resulted in a more cost effective and safe drug therapy [15].

Concerning the overall level of satisfaction towards the current clinical pharmacy services in the hospital; $72(51.8 \%)$ health professionals were poorly satisfied by the services while $31(22.3 \%)$ of respondents said they were fairly satisfied. This finding was inconsistent with another study conducted in the country in which physicians were satisfied role played by pharmacists with patients counseling concerning to safe and appropriate use of medication, involvement in side effect prevention and management, and preventing, detecting and resolving adverse drug reactions. Nevertheless, they were poorly satisfied with pharmacists' participation in ward rounds with other health care team, patient counseling during discharge, and documenting their services [12].

\section{Conclusion}

The study identified that majority of health professionals in selected public hospitals of west shoa zone had adequate knowledge and positive attitudes towards clinical pharmacy services but their practice with clinical pharmacists was found poor. It is recommended that collaborative working relationship should be established among health professionals in order to optimize and monitor drug use problem in the hospitals.

\section{Competing Interests}

The authors of this manuscript declare that they have no competing interests.

\section{Acknowledgements}

The authors would like to acknowledge all study participants and individual who provided information. We are also grateful to Ambo University for funding this research.

\section{References}

[1] Savigny D, Adam T. Systems thinking for health systems strengthening. Geneva: WHO Press; 2009.

[2] Remington. The science and practice of pharmacy. $21^{\text {st }}$ ed. Philadelphia: Lippincott Williams and Wilkins; 2006.

[3] FMOH, Ethiopian Hospital Reform Implementation Guidelines Volume 1. Addis Ababa: Ethiopia; 2010.

[4] American College of Clinical Pharmacy. The definition of clinical pharmacy. Pharmacotherapy 2008; 28: 816-817

[5] Sancar M, Okuyan B, Rabus SA, IzzettinFV. Opinion and knowledge towards pharmaceutical care of the pharmacists participated in clinical pharmacy and pharmaceutical care continuing education program. Turk J Pharm Sci 2013, 10: 245-254.

[6] WHO\&IPF. Developing pharmacy practice: a focus on patient care. Geneva: WHO Press; 2006.

[7] Awad A, Al-Ebrahim S, Abahussain E. Pharmaceutical Care Services in Hospitals of Kuwait. J Pharm PharmaceutSci 2006, 9: 149-157.

[8] Mekonnen AB, Yesuf EA, Odegard PS, Wega SS. Physicians' expectation of clinical pharmacists' role in Jimma University. International journal of pharmacy teaching and practice 2013, 4: $571-574$

[9] Abu-Gharbieh, Fahmy S, Abdul Rasool B. Attitudes and Perceptions of Healthcare Providers and Medical Students Towards Clinical Pharmacy Services in United Arab Emirates. Trop J Pharm Res, 2010; 9 (5): 421-430.

[10] Abu-Gharbieh E, Fahmy S, Abdul Rasool B. Attituds and Perceptions of Healthcare Providers and Medical Students towards Clinical Pharmacy Services in United Arab Emirates. Trop J Pharm Res 2010, 9: 430.

[11] Bryant L, Coster G, McCormick R. General practitioner perceptions of clinical medication reviews undertaken by community pharmacists. J Prim Health Care 2010, 2: 225233.

[12] Gelaw BK, Tegegne GT, Defersha AD. Knowledge, Attitudes and Practice of Physicians towards Clinical Pharmacy Services in Ten Public Hospitals in Oromia Regional State, Ethiopia. Epidemiology (Sunnyvale) 2017, 7: 323.

[13] Grussing PG, Goff DA, Kraus DM, Mueller CE. Development and validation of an instrument to measure physicians' attitudes toward the clinical pharmacist's role. Drug IntellClin Pharm 1984, 18: 635-640.

[14] Haxby DG, Weart CW, Goodman BW Jr. Family practice physicians' perceptions of the usefulness of drug therapy recommendations from clinical pharmacists. Am J Hosp Pharm 1988, 45: 824-827.

[15] Hepler CD. Clinical pharmacy, pharmaceutical care, and the quality of drug therapy. Pharmacotherapy 2004, 24: 1491-1498. 